\title{
Science and technology: when do they become front page news?
}

\begin{abstract}
Shirley Ramsey
This study suggests that press reports of science and technology increase in complexity, in depth and breadth of coverage, and in prominent placement in the news hole in relation to increased diversity or pluralism of supporting environments. It also suggests that system changes that produce interest and expanded knowledge of science provide opportunities for clashes of interests resulting in localized conflict and thus increased news coverage. 'Change' in an innovative area appears to link up conceptually in copy with theory, action descriptions, and visualization through metaphor. The study used content analysis to compare a more innovative, economically progressive 'research' area in the United States with an economically flat 'control' area; these areas were selected using National Bureau of the Census and local economic development office statistics.
\end{abstract}

\section{Introduction}

Most experts agree that scientific literacy is important to a nation's political and economic well-being; many educators also agree, however, that scientific literacy is tragically lacking in the United States. Some mass communication researchers believe that part of the problem is that serious press coverage of science and technology in the USA is limited to a few flagship newspapers, with local coverage being scant and often missing because sports, lifestyle, and other 'soft' news items are, more often than not, given priority in the news hole.

Editors and publishers would probably run more science stories if they believed their readership demanded more science news. The basic claim of this study is that societies and organizations do become more complex as they incorporate advanced scientific technologies into their service and production processes, and, as this occurs, more in-depth science reporting is required by citizens to help them understand how new technologies affect them. Moreover, increased coverage of science in the media will reflect deep-rooted change within local organizations and the community.

Ashby developed a theory and a formula to help explain how societies, organizations, or groups that either border another society or group, or serve another society or group with products or services, must either keep pace technologically with those they serve or neighbour, or risk extinction. Ashby termed such an increase in complexity 'requisite variety'.' Accordingly, if a community or society increases in scientific complexity and increases its use of technology, the media serving that community should likewise increase in-depth coverage of the activities; if traditional media do not respond to the community's new needs for scientific information, other media may 
soon fill the gap (in our culture, another source may provide the needed balance of information, often for profit).

Tichenor et al. found that basic societal change results from increasing pluralism in an audience (many voices, backgrounds, ethnicities, educational levels, technological expertises, etc.), and this leads to increased local conflict and increased reporting of such conflict. ${ }^{2}$ These authors viewed increased reporting of conflict as an indication of community or system change.

Fowler et al. observed that system or community change can be traced in the language of reporting where technological terms - often viewed as jargon by writing instructors - can be seen to be instances of new labelling. ${ }^{3}$ These authors maintain that 'made-up' or combination terms eventually become common knowledge in an audience, partially through experience with news reports (for example, terms such as 'microbiology' or 'antibiotic', or even 'microtechnology', are now in common use).

Tichenor coined the terms 'information of' science and 'information about' science to differentiate between scientific press reports that simply report scientific occurrences on the surface and those that attempt to explain occurrences in context, often through combining labelling such as that described by Fowler et al., with use of metaphor and other stylistic devices, to aid readers or listeners or viewers in understanding scientific processes. ${ }^{4}$ Utilizing concepts such as these, my 1988 study proposed two basic types of science writers: Information Brokers, who produce 'information of' science from more local scientific sources, and Authority Brokers, who appear to 'gatekeep' from within a more central part of the science network (utilizing more elite sources from centres such as Harvard, Stanford, Massachusetts Institute of Technology, and others of similar status). ${ }^{5}$ Here, writers designated as 'inner club' by Dunwoody ${ }^{6}$ appeared to help bridge the gap between the more universal modes of coverage of Authority Brokers and the more particularistic or local approaches of Information Brokers. Unanswered questions were: at what stage and under what conditions might more localized, less scientifically inclined Information Brokers be expected to take on the role of 'inner club' science writers and begin to build verbal bridges using an elaborated style of writing to do so? Also, what kinds of changes would prompt local editors and publishers to begin to feel the need to expand science coverage, perhaps even to put science articles on the front page?

In my 1989 study, I found that innovation or change in a community was linked to the nominating behaviour of local writers-that is, their tendency to interview local scientists as sources whose work was interesting and important in local development, and whose reputation was sufficiently well-grounded in the scientific community that they could then be picked up by the wire services or by national publications such as Scientific American. Thus local writers were 'nominating' sources from the periphery of the larger scientific world for expanded coverage in more central, policy-driven, authority-based, publications. ${ }^{7}$ The primary factor in that study, which seemed to differentiate between more expanded or in-depth coverage of science issues and more surface coverage, was language use. In the study, content analysis of science reports from a technologically developing area over three sampled years (from a period of eight years) showed significantly increased use of almost all figures of speech, which are viewed as devices useful for elaboration of ideas, contributing to development of abstractions or cognitions.

The purpose of the present study was to compare a developing area viewed as more 'innovative' in scope of science coverage with a "control" area, to determine if elaborative language elements and local coverage of science and of scientists might 
correlate with more obvious signs of change in a community. It was hypothesized that data would show the more innovative, 'research' community as significantly different from the "control' community in the following ways:

1. increased use of all elaborative devices, such as in figures of speech;

2. increased coverage of local sources and organizations;

3. increased number of items denoting clashes of interest and conflict;

4. increased use of combination terms; and

5. increased prominence of science articles in the news hole.

\section{Methodology}

Two similar communities were identified which exhibited particular significant differences. These differences implied that the two communities' newspapers would provide an opportunity to compare language items. One community was identified from National Bureau of the Census data on counties in the United States. and from county records, as being one of 20 areas in the United States developing at a rapid rate. This was the area around Research Triangle Park in North Carolina. The other area was identified through a campus development office as being in an area with a 'flat' economy, with only a tiny 'blip' on the economic scale produced during a brief expansionary period. This was an area around Tulsa, Oklahoma. The Tulsa area seemed to provide an ideal setting for the 'control' sample in that data showed it was more or less similar to other economic areas in the state, and that it had been on an economic plateau for a number of years; however, the brief expansionary period could show some indication of the language items in the study.

A census of articles was content-analysed for the Raleigh News and Observer and for the Tulsa World. Three sample years-1978, 1982 and 1986-were selected for the New's and Observer because they represented the time frame when the research triangle was undergoing extensive expansion. Adjacent years were selected for coding the World, except that collection was begun in 1976 in order to get a true picture before and after the 'blip' in the area's economic picture. This was necessary because otherwise the 'blip' could have produced misleading findings regarding customary language use in science coverage for the area. Thus the years sampled for this area were 1976 , 1980 and 1984.

Funds from a small grant and scholarships provided minimum wages for coders and graduate research assistants. Coders were trained to recognize elaboration devices and other study variables in articles (the article was taken as the basic unit of analysis). Reliability estimates were: North Carolina sample 77.6 per cent; Tulsa 78 per cent.

The concepts (variables) studied through content analysis were as follows.

(a) Total coverage: square inches of science coverage over eight years (three one-year sample populations) was tabulated for two newspapers, from two similar communities, one of which was considered a "control' community in that there had never been a concentrated effort there to attract large sums of money to develop a permanent home for high-tech research and development industries, as there had been in the 'research' community.

(b) News emphasis through placement in the news hole, or that newspaper area devoted to news after advertising space has been accounted for. Folio numbers were 
tabulated to determine whether or not there were differences in emphasis upon science news, whether such news ever appeared on the front page and, if so, under what circumstances; also, whether science news received emphasis by placement on page 1 in a special section, or was placed somewhere within a special section, or was placed at random throughout the newspaper.

(c) Identification of the 'given' piece of information in science articles through coding of theme repetition in articles ('given' was operationalized as the theme). In Clark and Haviland's definition of the 'given/new contract', they identified the part of the message the reader/sender recognizes and already knows as the 'given' in the message. They believe that this part of the message could be isolated as an important element in natural language redundancy. ${ }^{8}$ This element coordinates closely with the "new" variable, which is explained in item (d).

(d) Identification of the 'new' items presented to the reader. 'New' information items evolve from what has been 'given', therefore these two language components appear as complementary partners in the creation of new cognitive categories, or in the creation of new ways of thinking about familiar ideas or concepts. Integration of 'new' with 'given' is fundamental to understanding scientific concepts, so that there exists an unstated contract between what is known and what is not known about entities: one cannot move forward without the other.

(e) Visualization items were coded through the presence of metaphor in articles; metaphor is recognized by many as the verbal re-coding of reality in order to provide new images and ways of seeing things in a completely new light, according to Tourangeau and Sternberg. ${ }^{9}$

(f) Visualization items also were coded as simile.

(g) Transformation items operationalized as analogies. Hockett stated that human beings make new arrangements of form or function when they make analogies to older, more familiar, forms, in order to substitute one coded (cognitive) category for another, whether in thought, statement, or in deed. ${ }^{10}$

(h) Scripts of scientific and technological lore, as well as of scientific behaviours, were operationalized as use of anecdote.

(i) Creation of common myth was operationalized as use of the figure of speech personification.

(j) Socioeconomic change and diversification were operationalized in this study as items denoting local clashes of interests, or conflict (after Tichenor et al. ${ }^{2}$ ).

(k) Language indicators of system change incorporating new scientific elements were tabulated as combination terms, believed to be a measure of relexicalization by Fowler. $^{3}$

(1) Depth of scientific explanation in articles was operationalized as theoretical explanation of science concepts. Depth of cognition has been viewed by Anderson and Reder as the abstract, symbolic properties of a concept or a cognition, and explanation of theory seems to come close to this definition. ${ }^{11}$

(m) Breadth of scientific explanation in articles was operationalized as new behaviours or actions possible and explained as a result of scientific discoveries and breakthroughs. Anderson and Reder defined breadth of cognition as the number of cognitive elaborations available within a concept. "I

Regarding variables explained in (1) and (m), elaboration of communication, whether written or spoken, is believed by Anderson and Reder and many other theorists to encourage and be related to the deepening and broadening of ideation and/or conceptualization. Piaget, who is considered the father of developmental psychology, 
believed that concentrated elaboration of elements or symbols, as in language use or behaviour, helped individuals gain autonomy of action and behaviour. ${ }^{12}$ Nelson believed that autonomy of action involved development of organizing principles or schema, the concentration of which permitted qualitative leaps to new levels of understanding. Such schema are characterized as having both depth and breadth. ${ }^{13}$

(n) Presence of scientific development locally was operationalized as items in articles attributing science to local scientific sources, either individuals or organizations.

(o) Presence of cognitive cues in articles was operationalized as transitional items that 'point' and serve as mental road maps for explanation; an example of a cue might be 'first, look at the surface of this molecule: it is not as you expect, smooth and wrinkle-free; rather, it is cracked, like parched land . . .

(p) Coverage of local science by local science writers and reporters was coded as local byline and increased science coverage coming into the local system was coded for newswire services.

(q) Origination of the science news was coded as dateline. Generally, articles about science originate from some science centres in the country more than others; also, there was interest in seeing the extent to which there were any local datelines for wire service stories.

(r) Evaluation of the articles was coded as the standard positive, neutral, or negative.

(s) The number of attributions, overall, was also counted.

(t) The main topic and main concept of the coverage were coded.

Some examples of the study variables are given in the Appendix.

\section{Results}

Differences in square inches of science copy and in placement within the news hole or space available for news are apparent in Tables 1-3. Square inches of copy are significantly more in the North Carolina sample for the second and third sampling periods (Tables 2 and 3) even though the 1980 sampling year represented the 'peak' period in the Tulsa area. Not only were science and technology articles lengthier in the North Carolina sample, but these stories were more nearly placed on page 1 of a special section, or even on the front page of the newspaper for the last sampling period (Table 3). Folio placements showed significant differences between the two papers for all three sampled periods. This supports the hypothesis in that the more innovative 'research' community newspaper placed greater emphasis upon science and technology in terms of length of articles and folio placement.

Significant differences in science article placement in the publications can be explained by the following.

1. In the first year of sampling, the front page science articles were equally divided between the North Carolina and Tulsa samples; however, 73.3 per cent of articles on page 1 of a special section were from North Carolina, while 61.5 per cent in the Tulsa group were scattered throughout a special section $(p<0.006)$.

2. In the second year of sampling, 60 per cent of front page science articles were from the North Carolina sample; 75 per cent of special section page 1 articles were, however, in the Tulsa group $(p<0.004)$; note that this occurred even though this was the expansion period for the Tulsa area. 
Table 1. Differences between North Carolina and Tulsa newspapers: means, standard distribution and chi-square values for selected language items for the first sample period.

\begin{tabular}{|c|c|c|c|c|c|c|c|}
\hline & \multicolumn{2}{|c|}{$\begin{array}{l}\text { North Carolina, } 1978 \\
\text { (total science stories } \\
\qquad N=69 \text { ) }\end{array}$} & \multicolumn{2}{|c|}{$\begin{array}{c}\text { Tulsa, } 1976 \\
(N=92)\end{array}$} & \multirow[b]{2}{*}{ DF } & \multirow[b]{2}{*}{ Value } & \multirow[b]{2}{*}{ Prob. } \\
\hline & Mean & $\mathrm{SD}$ & Mean & $\mathrm{SD}$ & & & \\
\hline Average length (sq. ins) & 21.43 & 15.81 & 22.76 & 31.17 & 46 & 52.46 & 0.238 \\
\hline Folio ID or page found on & 2.86 & 0.74 & 2.69 & 1.06 & 4 & 14.27 & $0.006^{* *}$ \\
\hline Average paragraphs & 13.30 & 5.79 & 16.90 & 10.08 & 32 & 33.00 & 0.418 \\
\hline Average theme items & 23.88 & 14.18 & 4.27 & 2.41 & 10 & 24.29 & $0.007 * *$ \\
\hline Items new information & 17.35 & 19.01 & 0.98 & 1.52 & 9 & 27.39 & $0.001^{* *}$ \\
\hline Average use of metaphor & 2.73 & 7.44 & 0.07 & 0.30 & 3 & 2.64 & 0.449 \\
\hline Average use of simile & 0.99 & 2.77 & 0.41 & 0.86 & 4 & 12.12 & $0.016^{*}$ \\
\hline Average use of analogy & 1.57 & 6.48 & 0.34 & 0.96 & 5 & 12.09 & $0.033^{*}$ \\
\hline Average use of example & 4.79 & 10.28 & 0.78 & 1.08 & 5 & 5.71 & 0.335 \\
\hline Average use of anecdote & 2.00 & 9.51 & 0.35 & 0.81 & 5 & 9.82 & 0.080 \\
\hline Average use of personification & 3.98 & 8.77 & 0.08 & 0.31 & 4 & 5.03 & 0.284 \\
\hline Average use of conflict & 15.06 & 26.92 & 3.39 & 4.31 & 16 & 40.98 & $0.001^{* * *}$ \\
\hline Combination terms & 11.61 & 18.89 & 1.25 & 3.21 & 11 & 9.59 & 0.560 \\
\hline Theory explained & 7.28 & 9.13 & 0.86 & 1.05 & 5 & 1.99 & 0.850 \\
\hline Action described & 5.37 & 14.05 & 0.57 & 1.17 & 7 & 11.58 & 0.110 \\
\hline Local organizations & 0.57 & 1.00 & 0.39 & 1.05 & 6 & 14.21 & $0.027^{*}$ \\
\hline Cues or pointers & 0.55 & 0.96 & 0.08 & 0.35 & 2 & 13.75 & $0.001^{* *}$ \\
\hline Local by-line, newswire & 2.57 & 1.56 & 2.90 & 2.02 & 6 & 26.71 & 0.000 ** \\
\hline Dateline & 3.13 & 2.20 & 3.58 & 2.19 & 8 & 58.35 & $0.000^{* *}$ \\
\hline Positive/negative/neutral & 1.85 & 0.71 & 1.67 & 0.69 & 2 & 5.04 & 0.080 \\
\hline No. attributed sources & 1.86 & 1.63 & 3.58 & 3.14 & 12 & 20.65 & 0.056 \\
\hline
\end{tabular}

$* p<0.05 \quad * *<0.01$

3. In the third sampled year front page placement was once again fairly equivalent-46.1 per cent from North Carolina and 53.8 per cent from Tulsa-but once again the placement on page 1 of a special section was much greater in the North Carolina sample. Thus, for the three-year sampling period, the North Carolina group placed science and technology significantly more often on page 1 of special sections (and often on the front page). This finding would appear to support the hypothesis that the newspaper of the more innovative community would provide more prominent folio display for science articles.

An interesting 'thick' observation regarding science news in the two papers is that copy about science began increasing in the Raleigh News and Observer in the latter part of 1978, during the expansion of the Research Triangle. Increases in science coverage during the eight-year period occurred mainly in science-oriented news services or in locally produced copy. Local science coverage for 1978 was 385 inches, slightly more than 207 inches for 1982; coverage jumped to 984 square inches by 1986 . Coverage from The New York Times was up from 211 square inches in 1978 and 197 in 1982 , to 891 in 1986.

Meanwhile, Associated Press and United Press International coverage-less indepth science coverage provided by general newswire services-dropped during these sampled years. Knight-Ridder science coverage was picked up in 1986 for 40 square 
Table 2. Differences between North Carolina and Tulsa newspapers: means, standard distribution and chi-square values for selected language items for the second sample period.

\begin{tabular}{|c|c|c|c|c|c|c|c|}
\hline & \multicolumn{2}{|c|}{$\begin{array}{l}\text { North Carolina, } 1982 \\
\qquad(N=36)\end{array}$} & \multicolumn{2}{|c|}{$\begin{array}{l}\text { Tulsa. } 1980 \\
(N=73)\end{array}$} & \multirow[b]{2}{*}{ DF } & \multirow[b]{2}{*}{ Value } & \multirow[b]{2}{*}{ Prob. } \\
\hline & Mean & SD & Mean & SD & & & \\
\hline Average length (sq. ins) & 21.11 & 14.79 & 10.91 & 9.32 & 34 & 55.83 & $0.011^{* *}$ \\
\hline Folio ID or page found on & 2.94 & 0.79 & 3.32 & 0.80 & 3 & 13.32 & $0.004^{* *}$ \\
\hline Average paragraphs & 17.16 & 13.62 & 17.69 & 12.83 & 31 & 27.40 & 0.652 \\
\hline Average theme items & 24.02 & 18.48 & 2.87 & 1.81 & 11 & 11.81 & 0.378 \\
\hline Items new information & 14.40 & 13.94 & 5.64 & 3.46 & 14 & 48.65 & $0.000^{* *}$ \\
\hline Average use of metaphor & 1.40 & 3.24 & 0.24 & 0.59 & 3 & 5.84 & 0.119 \\
\hline Average use of simile & 0.80 & 2.16 & 0.13 & 0.45 & 2 & 0.40 & 0.814 \\
\hline Average use of analogy & 1.18 & 2.90 & 0.68 & 1.17 & 5 & 10.59 & 0.060 \\
\hline Average use of example & 4.02 & 7.37 & 2.17 & 3.16 & 10 & 26.60 & $0.003^{* *}$ \\
\hline Average use of anecdote & 0.69 & 2.20 & 0.98 & 2.16 & 8 & 8.34 & 0.390 \\
\hline Average use of personification & 10.61 & 18.35 & 0.34 & 0.91 & 4 & 5.22 & 0.260 \\
\hline Average use of conflict & 15.58 & 30.55 & 0.82 & 1.73 & 11 & 10.02 & 0.520 \\
\hline Combination terms & 15.61 & 25.35 & 2.46 & 2.76 & 12 & 28.36 & $0.005^{* *}$ \\
\hline Theory explained & 14.80 & 17.19 & 1.58 & 1.67 & 7 & 12.66 & 0.081 \\
\hline Action described & 2.74 & 5.67 & 1.79 & 2.73 & 8 & 26.30 & $0.001^{* *}$ \\
\hline Local organizations & 0.77 & 1.37 & 0.36 & 0.87 & 5 & 5.13 & 0.399 \\
\hline Cues or pointers & 0.13 & 0.35 & 1.10 & 1.95 & 7 & 15.35 & $0.032 *$ \\
\hline Local by-line, newswire & 3.11 & 1.76 & 2.60 & 1.67 & 7 & 13.14 & 0.069 \\
\hline Dateline & 3.16 & 2.17 & 4.76 & 2.40 & 9 & 33.89 & $0.000^{* *}$ \\
\hline Positive/negative/neutral & 1.72 & 0.56 & 1.79 & 0.72 & 2 & 0.64 & 0.725 \\
\hline No. attributed sources & 2.08 & 1.84 & 2.12 & 1.64 & 9 & 8.02 & 0.532 \\
\hline
\end{tabular}

$* p<0.05 \quad * * p<0.01$

inches of copy; coverage from all other scientific wire services increased from 14 square inches in 1978 to 120 in 1982 and 144 in 1986. In contrast, 56.3 per cent of all science copy for the Tulsa sample was Associated Press wire service copy, 3.94 per cent from the New York Times wire service, and little more than 4.5 per cent total from science wire services.

Thus, the pattern for an innovative community appears to be that science coverage from more scientifically oriented wire services increases, preceding more in-depth local coverage of technology and science. This appears to result from opening up the local system to innovative organizations and institutions. Apparently in more standard communities, although some science articles may flourish for brief periods of growth, there appears to be little reason for depth and breadth in articles prepared specifically for the science reader, unless there is accompanying infrastructural change. Thus, the developing cognitive frame built of imported science news varies from community to community.

Returning once more to data in Tables $1-3$, theme and new information appear significantly more in the North Carolina sample for 1978, the expansion period for Research Triangle Park. There is a continued significant difference for new information for the North Carolina sample in 1982, even though this was the Tulsa expansion period. According to the conceptualization of these variables, this would indicate 
Table 3. Differences between North Carolina and Tulsa newspapers: means, standard distribution and chi-square values for selected language items for the third sample period.

\begin{tabular}{|c|c|c|c|c|c|c|c|}
\hline & \multicolumn{2}{|c|}{$\begin{array}{l}\text { North Carolina, } 1986 \\
\qquad(N=59)\end{array}$} & \multicolumn{2}{|c|}{$\begin{array}{l}\text { Tulsa, } 1984 \\
(N=88)\end{array}$} & \multirow[b]{2}{*}{$\mathrm{DF}$} & \multirow[b]{2}{*}{ Value } & \multirow[b]{2}{*}{ Prob. } \\
\hline & Mean & SD & Mean & SD & & & \\
\hline Average length (sq. ins) & 37.28 & 24.00 & 15.40 & 10.45 & 46 & 84.84 & $0.000^{* *}$ \\
\hline Folio ID or page found on & 0.52 & 1.08 & 3.04 & 0.93 & 4 & 9.58 & $0.048^{*}$ \\
\hline Average paragraphs & 14.86 & 10.17 & 17.09 & 8.79 & 35 & 42.85 & 0.170 \\
\hline Average theme items & 31.14 & 31.05 & 3.12 & 5.71 & 14 & 18.10 & 0.202 \\
\hline Items new information & 31.65 & 28.12 & 7.65 & 7.13 & 22 & 28.63 & 0.150 \\
\hline Average use of metaphor & 5.93 & 11.37 & 0.35 & 1.22 & 5 & 5.15 & 0.397 \\
\hline Average use of simile & 2.09 & 5.12 & 0.23 & 0.62 & 3 & 1.77 & 0.621 \\
\hline Average use of analogy & 2.13 & 13.12 & 0.31 & 0.76 & 4 & 6.32 & 0.176 \\
\hline Average use of example & 6.03 & 16.40 & 1.52 & 2.40 & 8 & 16.78 & $0.032^{*}$ \\
\hline Average use of anecdote & 4.62 & 23.00 & 0.63 & 3.32 & 4 & 3.55 & 0.470 \\
\hline Average use of personification & 11.71 & 24.14 & 0.38 & 0.98 & 5 & 7.10 & 0.213 \\
\hline Average use of conflict & 47.23 & 62.22 & 2.86 & 4.14 & 19 & 21.12 & 0.330 \\
\hline Combination terms & 29.64 & 48.44 & 3.32 & 4.66 & 17 & 25.45 & 0.085 \\
\hline Theory explatined & 18.73 & 18.43 & 2.69 & 2.55 & 10 & 17.61 & 0.062 \\
\hline Action described & $5.4 ?$ & 10.10 & $2.6 ?$ & 2.79 & 11 & 36.25 & $0.000^{* *}$ \\
\hline Local organizations & 1.10 & 2.21 & 0.55 & 2.26 & 7 & 8.93 & 0.257 \\
\hline Cues or pointers & 0.52 & 1.08 & 1.32 & 1.60 & 6 & 26.33 & $0.000^{* *}$ \\
\hline Local by-line, newswire & 2.42 & 1.41 & 2.14 & 1.64 & 9 & 65.08 & $0.000^{* *}$ \\
\hline Dateline & 2.84 & 1.92 & 4.79 & 2.19 & 9 & 62.31 & $0.000^{* * *}$ \\
\hline Positive/negative/neutral & 1.66 & 0.68 & 1.63 & 0.80 & 3 & 5.39 & 0.145 \\
\hline No. attributed sources & 2.32 & 1.90 & 2.65 & 2.07 & 11 & 14.96 & 0.365 \\
\hline
\end{tabular}

$* p<0.05 \quad * * p<0.01$

growth in the amounts and kinds of scientific knowledge in use in the North Carolina community ('new information' was defined as the explanations of the theme as it was repeated throughout the articles).

Use of simile and analogy show up significantly more in the North Carolina sample for 1978, and use of example is significant for North Carolina in both 1982 and 1986 samples. There were no significant differences for the sampled years for anecdote or personification, although there appears to be greater use of these figures in the North Carolina sample. Support for the hypothesis of my first study is partial: use of analogy-a conceptual link with visualization and imagery-seems important in its striking appearance in the North Carolina sample in 1978. ${ }^{5}$

Items coded for confilict were significantly different in 1978 between the two communities, but were not significant for the other two periods; use of combination terms showed up significantly favoured in the North Carolina sample in 1982. Whereas usage of these items did not reach significance for the other two sampled periods, it seems clear the items were more pronounced in the North Carolina sample. Thus clearly there was support for the hypotheses that there would be increased use of these two indicators of increased diversity and change in the more innovative community.

Items depicting depth and breadth (theory explained and new behaviours and actions described) were generally more emphasized in the North Carolina sample, but 
significance between the items showed up only for breadth or action items and that was for the periods $1982 / 80$ and 1986/84. The next few items-local organizations as sources, local byline versus wire service and dateline-are important validation items.

Clearly sources from local organizations figure more prominently in the North Carolina sample, but are significantly different from the Tulsa group only for 1978 , the expansion period for North Carolina's Research Triangle Park. As is apparent from scrutinizing the articles from the sample, scientists from the park had begun to be interviewed for bylined stories - and, more important, a few of these stories were datelined for the area and went out over a wire service.

Significant differences in bylined articles highlight the following:

- 28.6 per cent of North Carolina and 12.9 per cent of Tulsa articles were written locally;

- 56.3 per cent of Tulsa articles and 26.2 per cent of North Carolina articles were Associated Press wire service stories, which were less complex generally than science stories from more scientifically oriented services;

- 22.5 per cent North Carolina to 3.9 per cent Tulsa articles were bylined science writers from The New York Times science news service, a more scientifically oriented service.

In addition, significance in datelines add additional analysis:

- 34.1 per cent of North Carolina articles in contrast to 0.3 per cent of Tulsa articles carried local bylines;

- other datelines for the two samples were relatively equivalent, except that North Carolina favoured New York datelines (61.7 per cent) while Tulsa favoured California datelines (69.8 per cent). This could suggest a New YorkNorth Carolina artery and also a continuing Oklahoma-California connection. However, the most significant fact throughout the byline/dateline analysis is that the North Carolina corridor was sufficiently developed technologically to attract national interest in the local dateline. Both samples were combined in one run to check for correlations for byline/dateline with language and other elaboration items. Only one strong relationship was found: dateline and actions (breadth) were positively related $(p<0.0003)$.

Thus these local bricoleur writers, acting originally as information brokers, became more likely to nominate scientists from the peripheral area for the larger science network-and became more likely to become inner club writers. The continuing relationship between the science experts and their increasingly literate media representatives would tend to promote the credibility of the organization and to push the media representative closer to inner club status. This certainly appeared to be the case with the innovative community in this study. This was taken as support for the second hypothesis. ${ }^{7}$

The presence of cues or pointers in articles was significant for all three sampled periods. This is an indication of lengthier, more explanatory articles, since brief stories hardly call for sentences or phrases directing the reader along the mental path the writer is about to take or what scientific thesis he or she is about to explicate. There was no significance for positive or negative bias in stories, nor was there any level of difference between the sampled newspapers for the number of attributions in stories.

Increased coverage of science and technology within local organizations, for both samples, seemed to be related to reiteration of theme, new information, explanations 
of theory, and number of attributions, as shown in Table 4. Where the two samples differed, however, was that the North Carolina coverage linked local organizations significantly with lengthier articles, more prominent folio placement, use of metaphor, simile, and most importantly, conflict and combination terms.

Increased coverage of science within local organizations, for both samples, may be seen to be related to reiteration of theme and new information, explanation of theory, and number of attributions. Where the two samples differ, however, is that coverage of the more innovative area links local organizations significantly with lengthier articles, more prominent placement, use of metaphor and simile and, most importantly, conflict and combination terms (it is interesting that the standard versions of stories show significant association with more positive approaches).

\section{Discussion}

This study suggests that press reports of science and technology increase in complexity and in depth and breadth of coverage in relation to the increased diversity or pluralism of the area of coverage. It also suggests that community, organization, or group (system) changes that produce interest and expanded knowledge of science provide opportunities for clashes of interests resulting in localized conflict; it is the

Table 4. Correlation of local organizations in technology articles with other items for both samples.

\begin{tabular}{lrlrll}
\hline & \multicolumn{2}{c}{ North Carolina } & \multicolumn{2}{c}{ Tulsa } \\
\cline { 2 - 3 } \cline { 5 - 6 } & $(N=164)$ & Prob. & $(N=254)$ & Prob. \\
\hline Square inches & 0.3044 & $0.0001^{* *}$ & 0.0047 & 0.9402 \\
Page article on & -0.1122 & 0.1524 & -0.1835 & $0.0033^{* *}$ \\
No. paragraphs & 0.4375 & $0.0001^{* *}$ & 0.0975 & 0.1209 \\
Times theme mentioned & 0.3581 & $0.0001^{* *}$ & 0.4908 & $0.0001^{* *}$ \\
New information & 0.3838 & $0.0001^{* *}$ & 0.3315 & $0.0001^{* *}$ \\
Metuphor & 0.3695 & $0.0001^{* *}$ & 0.0969 & 0.1234 \\
Simile & 0.1541 & $0.0487^{*}$ & 0.0037 & 0.9522 \\
Analogy & -0.0393 & 0.6168 & -0.0276 & 0.6605 \\
Example & 0.1456 & 0.0628 & -0.0418 & 0.5071 \\
Anecdote & 0.2391 & $0.0020^{* *}$ & 0.6491 & $0.0001^{* * *}$ \\
Personification & 0.1168 & 0.8820 & -0.0681 & 0.2791 \\
Conflict terms & 0.1897 & $0.0149^{*}$ & -0.0147 & 0.8154 \\
Combined words & 0.4598 & $0.0001^{* *}$ & 0.0375 & 0.5513 \\
Times theory explained & 0.3923 & $0.0001^{* *}$ & 0.3249 & $0.0001^{* *}$ \\
Actions explained & 0.1483 & 0.0580 & -0.0208 & 0.7410 \\
Cues or pointers & 0.0086 & 0.9130 & -0.0226 & 0.7192 \\
Local by-line or newswire & -0.2225 & $0.002^{*}$ & -0.1867 & $0.0022^{* *}$ \\
Dateline & -0.3441 & $0.0001^{* *}$ & -0.0563 & 0.3711 \\
Direction article & -0.0834 & 0.2879 & 0.2140 & $0.0006^{* *}$ \\
No. attributed sources & 0.1597 & $0.0410^{*}$ & 0.1288 & $0.0402^{*}$ \\
Main topic & 0.0125 & 0.8731 & -0.1017 & 0.1059 \\
Main concept & 0.0046 & 0.9529 & 0.0769 & 0.2215 \\
M & & & & \\
\hline
\end{tabular}

$* p<0.05 \quad * * p<0.01$ 
news convention of coverage of conflict that makes it possible for writers and editors to find more prominent placement in the news hole for science coverage.

Use of figures of speech and other items for language elaboration usually appear in lengthier scientific reports in the media; however, whether or not these lengthier reports represent imported information, as in wire service reports, or internal and often exported information about science, seems to be related to the development and innovative nature of the coverage area. Thus expanded science coverage in local media seems to be related not to a need for scientific literacy as educators would like to believe, but to the degree to which science and technology have actually taken root and created change within the coverage area.

This appears to be an agenda-building process: local science writers, through increased contact with scientists in their areas due to technological growth in the area (and through organizational efforts to put scientists in contact with media representatives) make the transition from information brokers to bricoleur writers who begin to 'cobble together' pieces of scientific information in elaborated fashion for a more pluralistic coverage area. Future studies could include surveys that attempt to trace relationships between science writers and their local sources, as I did for a previous study.

\section{Appendix}

The following are examples of the study variables taken from one article in the North Carolina sample; the stories from the Tulsa sample are not nearly as consistently laden with study variables, and, when they did appear, they were almost always in imported (wire) copy. The following examples come from a story about a revolutionary agricultural technology.

Theme (given information from the lead and headline): agricultural bonanza

$\mathrm{New}$ information (derived from what has been given but provides new cognitive input): high technology plant-growing technique involving cloning (repeated in various ways throughout the article)

Depth (theoretical or scientific explanations): 'Tissue culturing, an advanced version of growing flowers from cuttings instead of from seeds, has become a hot topic among scientists.'

Breadth (behavioural or scientific options evolving from the new technology): "In only 12 additional weeks [these] methods have grown flowering fruit producing grape vines. In 40 days they have produced flowering miniature roses. Dates have fiowered in only three years, 12 to 22 years ahead of schedule.'

Combining forms or combination w'ords: 'tissue culture'

Conflict terms: ". . plans to reveal more about his "maturity factor" next May when he becomes president of the International Horticultural Society. For now, he warned that the technique needs more testing.'

Metaphor: dwarf (apple) plants 'that produce apples in a year'

Simile: 'apples growing like row crops'

Personification: "when the young clones are removed from their jars and planted' 
Anecdotal: ". . said cloning. coupled with early maturity, could revolutionize such budding native North Carolina industries as Christmas tree and ginseng cultivation, in addition to apple and grape production.'

Example: 'roses blooming quicker than chrysanthemums'

Analogy: researcher compared his cloning technology to the 'microchip industry'

Dateline for this article is Chapel Hill; byline was for a Raleigh, North Carolina writer (one recognized as appearing throughout this sample for increased coverage of local science and technology)

Organizations: local, plus international, plus one in Australia

There were several other instances of these study variables appearing throughout this one article.

\section{References}

1 Ashby, W. R., 1956, Variety, constraint, and the law of requisite variety. An lmuroduction to Cybernetics (London: Chapman \& Hall), Chap. 7, pp.123-134.

2 Tichenor, P., Donohue, G. A., and Olien, C. N., 1980, Community Conflict and the Press (Beverly Hills, CA: Sage).

3 Fowler, R., Hodge, B., Kress, G., and Trew, T., 1979, Language and Control (Boston, MA: Routledge \& Kegan Paul).

4 Tichenor, P., 1965, Communication and knowledge of science in the adult population in the US (unpublished dissertation, Stanford University).

5 Ramsey, S., 1988. Communicative competence for the science interview: information brokers and authority brokers. Journalism Monographs, No. 107 (October).

6 Dunwoody, S. L., 1978, Science journalists: a study of factors affecting the selection of news at a scientific meeting (doctoral dissertation, Indiana University, Bloomington).

7 Ramsey, S., 1989, The role of technological development in setting the stage for expanded science coverage. Southurestern Mass Commumication Sournat. 5(2), 33-40.

8 Clark, H. H., and Haviland, S. E., 1977, Content Analysis of Conmunications (New York: Macmillan).

9 Tourangeau, R., and Sternberg. R. J., 1982, Understanding and appreciating metaphors. Cognition, II, 203-244.

10 Hockett, M., 1980, A Course in Modkrn Linguistics (New York: Macmillan).

11 Anderson, J. R., and Reder, L. M., 1979, An elaborative processing explanation of depth of processing. Levels of Processing in Hunan Mennry, edited by L. S. Cermak and F. Q. M. Craik (Hillsdale, NJ: Lawrence Erlbaum), pp.385-403.

12 Paiget, J., 1926. The Language and Thought of the Child (New York: Harcourt, Brace \& World).

13 Nelson, K., 1973, Structure and strategy in learning to talk. Monograph of the Society' for Research in Child Development, 38 (Whole No. 149).

\section{Author}

Shirley Ramsey is an associate professor at the H. H. Herbert School of Journalism and Mass Communication, University of Oklahoma, 860 Van Vleet Oval, Rm 101, Norman, Oklahoma 73019-0270, USA. 